\title{
Dizeres e práticas docentes: as discussões de gênero em uma escola pública estadual de Pio XII/MA*
}

\author{
Rarielle Rodrigues Lima** \\ Marília Milhomem Moscoso Maia** \\ Sandra Maria Nascimento Sousa*****
}

\section{Resumo}

Este artigo tem por objetivo refletir sobre as compreensões de gênero/sexualidade de professores (as) de uma escola pública estadual do município de Pio XII, no estado do Maranhão, em especial, o material construído em 2015 a partir do caderno de campo e rodas de conversa, referente à formação pedagógica ocorrida no mês de abril do mesmo ano. A partir das contribuições de Judith Butler (2015), Michel Foucault (2004; 2005) e Jacques Derrida (2004; 2015), problematiza-se o entendimento sobre a categoria gênero/sexualidade apresentada durante a formação pedagógica, em uma perspectiva pósestruturalista.

Palavras-chave: Gênero, Educação básica, Formação pedagógica.

\footnotetext{
* Recebido em 03 de abril de 2018, aceito em 03 de novembro de 2020.

** Doutora em Ciências Sociais, Universidade Federal do Maranhão (UFMA), São Luís, MA, Brasil. rariellerodrigues@gmail.com / https://orcid.org/0000-0001-8494-302X

*** Mestra em cultura e sociedade, Universidade Federal do Maranhão (UFMA), São Luís, MA, Brasil. mariliamilhomem@gmail.com / https://orcid.org/0000-0002-6524-5063

**** Docente da pós-graduação em Ciências Sociais e em Cultura e Sociedade, Universidade Federal do Maranhão (UFMA), São Luís, MA, Brasil; coordenadora do Grupo de Estudos Gênero, Memória e Identidade -GENI, na mesma universidade. sandraufma@gmail.com / https://orcid.org/0000-0001-9501-7363
} 
Sayings and practices of teaching: gender discussions in a public school in Pio XII, Maranhão

\begin{abstract}
This article reflects on understandings about gender / sexuality expressed by teachers at a public school in the municipality of Pio XII, Maranhão. It analyses material constructed in 2015 in a field notebook and through conversational circles, which considered pedagogical training on the subject . Theoretical contributions from Judith Butler (2015), Michel Foucault (2004; 2005) and Jacques Derrida $(2004 ; 2015)$ are used to discuss and problematize understandings about the category gender/sexuality presented during the pedagogical training, in a post- structuralist perspective.
\end{abstract}

Keywords: Gender, Basic education, Pedagogical training. 


\section{Introdução}

Hoje, 08/03/15, nos reunimos na sala dos (as) professores (as) para elaborarmos o cronograma de formação de 2015, elencando os temas que serão abordados durante o ano letivo. Sugeri como temática as discussões sobre gênero e sexualidade na escola pontuando que eu estava em processo de elaboração de dissertação sobre o tema, na tentativa de estabelecer uma ponte para essas discussões na nossa escola. A proposta não foi muito bem aceita, pois alguns/algumas professores (as) se posicionaram contra ela por justificarem que isso era dever da família e não da escola. No entanto, ao final da reunião, depois de minha explanação e justificando como seria a capacitação, realizaríamos um encontro para entendermos sobre gênero e sexualidade, relacionando com o cotidiano escolar $e$ estabelecendo pontos de reflexão sobre comportamentos, gestos e ações em momentos de violência no que diz respeito às temáticas de gênero e sexualidade. A proposta então foi aceita e seria a primeira a ser realizada em abril sob minha responsabilidade (Trecho caderno de campo, 08/03/15, Pio XII/MA).

Apresenta-se, de início, o trecho acima, retirado de um caderno de campo, para destacar que os espaços de fala são construídos em meio a disputas de poder, onde se concebem temas/temáticas do que se pode e do que não se pode ser dito, especialmente em espaços educativos como a escola. Discutir sobre as relações sociais de gênero nos espaços escolares permite compreender como a instituição escolar em seus discursos cotidianos reforça, atualiza e desloca os entendimentos sobre o que é ser "homem" ou "mulher". Pensando-se sob uma perspectiva pós-estruturalista e a partir das contribuições teóricas de Judith Butler (2015), pode-se compreender as multiplicidades pertencentes à fluidez de reconhecimentos de si em relação aos outros. O gênero, a partir dessa lógica, é relacional. Desse modo, a problemática central deste trabalho é analisar quais são as compreensões de gênero acionadas pelos(as) professores(as) nos diferentes lugares da escola (pátio, sala dos(as) professores(as), reuniões, sala de aula) e como elas direcionam e orientam práticas pedagógicas do dia-a-dia da escola.

Os questionamentos acima demarcam a nossa inquietude no que diz respeito ao entendimento sobre as construções de práticas pedagógicas cotidianas ${ }^{1}$ no espaço escolar, visibilizando as concepções de gênero dos(as) diversos(as) atores(as) sociais que compõem e instituem esse espaço educacional de produção de gênero.

As aproximações que se estabeleceram durante a escrita deste artigo sobre as compreensões de gênero foram construídas a partir das leituras de Judith Butler (2015), Michel Foucault (2004; 2015) e Jacques Derrida (2004; 2005). Em face disso, propõe-se refletir sobre as compreensões de gênero/sexualidade de professores(as) tendo como material de análise as informações obtidas nas rodas de conversa e anotações de campo realizadas no ano de 2015, no município de Pio XII, no estado do Maranhão, especialmente durante a capacitação de formação de professores(as) na semana pedagógica sobre a temática gênero/sexualidade ocorrida em abril do mesmo ano, em uma escola da rede estadual de ensino público.

Diante do exposto, o presente artigo organiza-se a partir da apresentação do contexto escolar $e$ das relações que envolvem os espaços escolares como território de conhecimento e de disputas. Em seguida, abordam-se as discussões de gênero e sexualidade a partir das contribuições das polifonias ${ }^{2}$ discursivas dos(as) professores(as) com recortes das falas da roda de conversa e finalizase com algumas considerações sobre a experiência compartilhada pelos(as) professores(as) durante a semana pedagógica. É importante ressaltar que todos(as) os(as) professores(as) assinaram o Termo de Consentimento Livre e Esclarecido (TCLE) e tiveram seus nomes suprimidos para preservação de suas identidades.

\footnotetext{
1 Como práticas pedagógicas cotidianas entendemos as ações que são desenvolvidas no dia a dia da escola, para além da conceituação formal do conteúdo em sala de aula.

2 Destacamos a polifonia discursiva para evidenciar as falas que professores(as) construíram no decorrer da capacitação na semana pedagógica de 2015.
} 


\section{Compreensões sobre gênero e escola}

A escola como instituição, na perspectiva foucaultiana ${ }^{3}$ (Foucault, 2014), é utilizada por seus agentes para engendrar corpos e direcionar comportamentos e ações que favoreçam a docilidade, construindo uma lógica do que deve ser apreendido $e$ incorporado durante os anos escolares em um campo de disputa de poderes e de resistências. Assim, a instituição escolar condensa, dissipa e propaga informações que são utilizadas e retomadas em algum momento nas relações sociais.

Desse modo, se posicionar utilizando os espaços de fala concedidos (ou melhor, conquistados) aos(as) professores(as) dentro da estrutura do sistema escolar é uma forma útil de desconstrução e desnaturalização de ações discursivas inscritas nos corpos dos sujeitos no processo de escolarização. Embora as discussões sobre gênero/sexualidade 4 não sejam recentes nos currículos escolares no Brasil, de acordo com Helena Altmann (2001), elas se iniciam por volta da década de 1970, inicialmente, como disciplina de educação sexual, para, em 1999, serem reconhecidas como temas transversais de orientação sexual, a partir dos Parâmetros Curriculares Nacionais (PCN). Esses documentos educacionais balizavam as ações dentro da escola e da sala de aula apresentando o viés das Ciências Médicas e Biológicas que consolidavam esses discursos como naturais, não como construções sociais e históricas. Nesse sentido, mesmo que estabelecessem fissuras às propostas de intervenção sobre gênero e sexualidade, a princípio, reforçaram as demarcações do que "era feminino" e do que "era masculino" dentro de uma perspectiva binária, onde o "recatamento" seria para as meninas e a "liberdade" para os meninos.

Desde o surgimento da categoria e dos estudos de gênero, problematizam-se os modos de produção daquilo que é admitido e aceito como verdadeira Ciência. Feministas e pós-estruturalistas criticavam os sistemas universais e genéricos, questionando os limites $e$ as crenças no papel da verdade e do seu valor estável, abrindo espaços para reavaliações, mudanças e transformações. Teresa de Lauretis (1987) destaca que

[...] um quadro de referência feminista que sirva para tudo não existe. Ele tampouco deveria, jamais, ser um pacote pronto para usar. Nós precisamos continuar construindo esse quadro, um quadro absolutamente flexível e reajustável, a partir da própria experiência das mulheres com relação à diferença, a partir de nossa diferença em relação à mulher e das diferenças entre as mulheres; diferenças [...] que são percebidas como tendo a ver tanto (ou mais) com a raça, a classe ou a etnia quanto com o gênero ou a sexualidade per se (Lauretis, 1987:14).

Sendo assim, com o avanço dos estudos de gênero e feministas, foi possível a construção de espaços e formas para que o sujeito subalterno pudesse falar e ser ouvido, no sentido de que "não se pode falar pelo subalterno, mas pode-se trabalhar 'contra' a subalternidade, criando espaços nos quais o subalterno possa se articular e, como consequência possa também ser ouvido" (Spivak, 2010:14). A construção e aprovação de documentos educacionais como o Plano Nacional de Educação (PNE ${ }^{5}$ ), no ano de 2014, proporcionou a intensificação das discussões sobre gênero/sexualidade no cotidiano escolar, evidenciando pelo menos dois polos: um que reduz a problemática a justificativas que visam à manutenção do status quo, como o da desvirtuação de comportamentos e de condutas dos(as) alunos(as), questionando a relação entre pessoas do mesmo sexo no ambiente escolar; outro que problematiza as naturalizações constituídas no processo de socialização nos espaços escolares, tornando invisíveis as diversidades dos agentes não enquadrados na matriz normativa ${ }^{6}$ - eles usam os espaços escolares resistindo às violências $e$

\footnotetext{
${ }^{3}$ Destacamos como perspectiva foucaultiana os entendimentos que Foucault (2014) traz em sua obra Vigiar e Punir, destacando o capítulo Corpos Dóceis.

4 Estabelecemos a grafia gênero/sexualidade por entender que ao se falar sobre gênero não há dissociação em se falar sobre sexualidade, embora não sejam conceitos equivalentes.

5 O Plano Nacional de Educação (PNE) é uma lei cuja edição periódica é a cada 10 anos, assim o PNE 2014 até 2024 , estabelecendo as diretrizes e metas para o desenvolvimento nacional, estadual e municipal da educação. Desse modo, o Plano vincula os entes federativos às suas medidas e os obriga a tomar medidas próprias para alcançar as metas previstas. Ao final de sua vigência, esperas-se alcançar as metas estabelecidas para a melhoria da educação.

${ }^{6}$ Designa a grade de inteligibilidade cultural por meio da qual os corpos, gêneros e desejos são naturalizados [...] [caracterizando] o modelo discursivo/epistemológico hegemônico da inteligibilidade do gênero, o qual presume que, para
} 
discriminações. Esses polos destacados são usados como forma de situar os campos de disputas discursivas de poder. Não se pretende limitá-los em suas complexidades, mas posicioná-los em relação ao segundo ponto que problematiza as naturalizações.

\begin{abstract}
Estávamos em reunião na sala dos/as professores/as para pensarmos como seria a formação pedagógica do mês de abril na Escola Aprendizado ${ }^{7}$, várias temáticas foram levantadas (metodologia de ensino, ferramentas pedagógicas, TICS), sugeri discutir gênero e sexualidade na escola [...] o alvoroço começou, pois as opiniões divergiam com algumas alterações no tom de voz. Após a explanação de justificativa, a responsabilidade de organizar o processo foi direcionada a mim, pois a solicitação demarcou o distanciamento dos/as professores/as à temática: "Você que estuda isso ver como vai fazer" (Trecho caderno de campo, 08/03/15, Pio $\mathrm{XII} / \mathrm{MA})$.
\end{abstract}

Quando foram propostos os debates de gênero e sexualidade na escola durante uma reunião de planejamento pedagógico, o desconforto gerado pela simples possibilidade de se abordar a temática em um processo de capacitação de professores(as) e de discussões para o aprimoramento das ações pedagógicas evidencia a percepção de que, embora os estudos teóricos sejam vastos, sua materialização no cotidiano escolar ainda é reduzida e silenciada. Embora se tenha avançado nas produções teóricas de gênero e sexualidade, a interlocução das ações debatidas na academia necessita de mediadores para, também, estabelecer-se na educação básica.

As discussões de gênero e sexualidade se estabelecem com mais intensidade nas universidades, porém, quando pensamos a educação básica, a linguagem utilizada dificulta o entendimento de quem está na base. As mediações estabelecidas pelos grupos de pesquisa e por pesquisadores(as) que apresentam a escola como campo de estudo têm se constituído como elemento importante para efetivação do debate sobre a temática na escola. O elo entre universidade e educação básica passa pela construção de momentos de formação com professores(as).

Partindo da compreensão de Teresa de Lauretis (1994) sobre tecnologia de gênero e classificando a escola como uma dessas tecnologias, podemos articular e tangenciar que os modos como são diluídas as possibilidades de entendimento de gênero cristalizam a representação da heteronormatividade como única via de entendimento acessível, fixando, de certo modo, as representações de "homem" $e$ "mulher". Pois, para a autora "O gênero, como representação e como autorrepresentação, é produto de diferentes tecnologias sociais, como cinema, por exemplo, $e$ de discursos, epistemologias e práticas críticas institucionalizadas, bem como das práticas da vida cotidiana" (Lauretis, 1994:208).

Compreender gênero e sexualidade como construções históricas, sociais, culturais e políticas, como propõe Judith Butler (2015), amplia as discussões sobre o que se entende por essas categorias, além de tornar visível a sua dinamicidade. Assim, a partir dessa percepção, entende-se gênero/sexualidade como

o fato de a realidade do gênero ser criada mediante performances sociais contínuas significa que as próprias noções de sexo essencial e de masculinidade ou feminilidade verdadeiras ou permanentes também são constituídas, como parte da estratégia que oculta o caráter performativo do gênero $e$ as possibilidades de proliferação das configurações de gênero fora das estruturas restritivas da dominação masculinista e da heterossexualidade compulsória (Butler, 2015:244).

Pensar gênero no cotidiano escolar por essa perspectiva desloca as possibilidades de representação da fixidez da heteronormatividade, com seus polos opostos e hierarquicamente demarcados, para uma construção constante e fluída de performatividades de gênero.

os corpos serem coerentes e fazerem sentido (masculino expressa macho, feminino expressa fêmea), é necessário haver um sexo estável, expresso por um gênero estável, que é definido oposicional e hierarquicamente por meio da prática da heterossexualidade (Butler, 2015:258).

7 Nome fictício para garantir o anonimato dos/as participantes. 
Esta compreensão de gênero/sexualidade construída/desconstruída por Judith Butler (2015) baseou este texto e fundamentou as discussões estabelecidas no período da formação pedagógica entre os dias 10 e 11 de abril de 2015 proposta aos(as) professores(as) da escola Aprendizado no município de Pio XII, no Estado do Maranhão.

A escola Aprendizado está estabelecida na sede do Município de Pio XII e atende alunos(as) com idades entre 14 e 20 anos, nos turnos diurno e noturno, ofertando ensino médio regular e Educação de Jovens e Adultos (EJA). A maioria de seu alunado é negra ou parda e heterossexual. Nos turnos vespertino e noturno predominam os(as) alunos(as) da zona rural. A capacidade de atendimento de estudantes nas sete turmas distribuídas por turnos é de 500 alunos(as) no total.

Seu quadro de funcionários possui 35 professores(as), dois gestores, duas zeladoras, três vigias, uma merendeira, duas técnicas-administrativo. As idades variam entre 30 e 56 anos de idade, $60 \%$ são negros/pardos e $46,6 \%$ são mulheres.

\section{Falando sobre gênero: aproximações e distanciamentos na formação pedagógica}

A formação ocorreu no dia 10 de abril de 2015 mediada por uma professora e teve dois momentos de organização: um primeiro, em que foram apresentadas as conceituações de gênero $e$ o início da sensibilização sobre a temática na escola, e um segundo, no qual os(as) professores(as), a partir de relatos e reportagens, deveriam elaborar possibilidades de discussão sobre gênero/sexualidade no cotidiano de suas aulas. Nos dois dias de formação participaram, no total, um quantitativo de 35 professores(as) (19 homens e 16 mulheres)

As cadeiras foram organizadas em formato de círculo para que todos (as) os (as) participantes tivessem uma visão ampliada da sala e ninguém pudesse se esconder. Todos (as) professores (as) estavam frente a frente e lado a lado. [...] Estavam inquietos (as), talvez ansiosos (as) pelo que seria dito e como seria feito. Canetas eram batidas nas carteiras e os papéis de anotações dobrados e redobrados constantemente (Trecho caderno de campo, 10/04/15, Pio XII/MA).

$\mathrm{O}$ primeiro encontro foi mobilizado a partir do questionamento: $\mathrm{O}$ que você entende por gênero/sexualidade? Foi possivel perceber como estavam organizadas as ideias sobre a temática entre os(as) professores(as) e quais seriam os discursos dominantes quando se oportuniza o debate de gênero/sexualidade. Notou-se que, em todas as falas proferidas nesse primeiro momento, foram utilizados os termos homem e mulher, que evidenciam a polaridade de classificação dos corpos. Alguns(mas) professores(as) ficaram em silêncio e/ou simplesmente concordaram com as falas dos(as) demais.

Destaca-se a seguir algumas falas dos(as) professores(as) participantes da formação pedagógica.

"Gênero só tem o masculino e o feminino. Já a sexualidade pode ser heterossexual, homossexual e bissexual, né?! [dar de ombros ao fazer a pergunta]" (Professor A, 10/04/15, roda de conversa).

"Eu sei que tu vais falar mais coisa [coça a cabeça], mas pra mim é quando a gente fala de homem e mulher [risos]" (Professora B, 10/04/15, roda de conversa).

"Eu não entendo nada. Eu vim aqui pra saber [olha para os lados], já ouvi muitos comentários, mas eu sei que tem gay, lésbica, não é? [gesticula como se quisesse o apoio dos (as) demais]" (Professor E, 10/04/15, roda de conversa).

Pela maneira como os(as) professores(as) reagiram à pergunta, o desconforto que sentiram ao falar sobre gênero e sexualidade fez-se visível. Deve-se ter em vista que os reconhecimentos sobre a temática já carregam consigo inúmeros significados e que, naquele momento, colocavam a discussão da temática em segundo plano. Assim, não houve, explicitamente, questionamento acerca do porquê da capacitação ou argumentos que desmerecessem a discussão, mas era notório o incômodo de uma boa parte dos(as) professores(as).

Após esse contato, foi exibido o curta-metragem intitulado $A$ maioria oprimida (Majorité Opprimée), de Eleonore Pourriat (2010), que retrata uma sociedade em que são invertidas as 
representações de submissão, da feminina pela a masculina, com o objetivo de desestabilizar acontecimentos rotineiros de violência e abusos que passam "despercebidos" no nosso dia a dia.

Os 10 minutos do curta-metragem apresentam o cotidiano de Pierre, o marido cuidador do lar e do filho. Assim, visualizamos um dia de sua vida. O início é marcado pela movimentação de mulheres em diferentes espaços, como uma corrida matinal sem camisa. Pierre surge na caixa do correio empurrando o carrinho da criança e encontra uma vizinha que coloca o lixo na lixeira enquanto ele confere as correspondências. A vizinha comenta sobre a organização do condomínio, mas rapidamente se corrige, evidenciando que não é ele quem resolve essas coisas, e sim sua esposa.

Pierre leva seu filho à creche, que é coordenada por seu amigo Nissar, um mulçumano vestido com uma burca preta. Nissar é repreendido por Pierre por se submeter aos desejos de sua esposa, pois estava sem barba e de burca. Nissar responde que é assim que Deus quer. No caminho de volta, já andando de bicicleta, abrindo um botão da camisa, quando para no sinal, Pierre é abordado por uma moradora de rua que lhe dirige frases bastante pejorativas. Ele continua seu caminho e, após rebater as falas de quatro mulheres que estavam na rua, sofre violência sexual. Após o ocorrido, vai à delegacia prestar depoimento, sempre puxando para baixo, para cobrir-se, a bermuda que vestia. Na delegacia, as policiais desdenham da sua queixa e, ao ler a descrição da violência, tendem a desconsiderá-la, mesmo sendo visíveis os ferimentos de Pierre. Sua esposa, Marion, então vai buscá-lo no hospital, mas perde a paciência com o marido, pois a reclamação do ocorrido, a dor e todos os problemas são culpa do "masculinismo", e diz que está exausta. Marion deixa Pierre sozinho. A cena final enquadra Marion caminhando por uma larga avenida, ouvindo xingamentos sussurrados.

Em seguida, reabrimos a roda de conversa sobre as informações apresentadas no curta. A partir dela, destacamos algumas significativas falas dos(as) professores(as):

\footnotetext{
"Nossa, como essas coisas passam com a gente que nem percebemos direito [olhar de espanto $e$ choque, tampando a boca com a mão]" (Professora C, 10/04/15, roda de conversa).

"Incômoda ver que isso choca agora, mas a gente acha tão normal quando é o homem fazendo" (Professor F, 10/04/15, roda de conversa).

"É estranho ver mulheres fazendo algo que é da natureza do homem" (Professor D, 10/04/15, roda de conversa).

"O documentário faz a gente pensar bastante" (Professora G, 10/04/15, roda de conversa).

"Chega a ser nojento ver isso, mas até nós mulheres, reforçamos essas ações [pensativa]" (Professora I, 10/04/15, roda de conversa).
}

As impressões relatadas pelos(as) professores(as) foram de desconforto, na medida em que pequenas ações "não" se encaixavam em suas respectivas representações. Achar estranhas algumas cenas do curta, como as que retratavam o assédio exercido pelas mulheres em relação aos homens que passavam na rua, desloca um ponto de visão da "normalidade" e de "natureza humana" sobre esses comportamentos tidos como naturais do homem. Os deslocamentos oportunizados pelo curtametragem possibilitaram questionar atitudes e ações que são propagadas cotidianamente. Evidenciam a polaridade estabelecida de controle para homens e a submissão para as mulheres, marcações essas que são representadas em todo o curta.

Jacques Derrida (2005), ao falar sobre gramatologia, apresenta instrumentos que possibilitam o entendimento de como a escritura determina o conjunto de ações e repertórios que farão parte de um imaginário de reconhecimento mútuo - o que nos leva a pensar como esse processo de consolidação do que é expresso e prescrito das referências de gênero é construído nas pequenas relações cotidianas. Nesse sentido, as ações expressas no curta demonstram as fissuras na construção normativa de gênero, apresentando outra possibilidade de reconhecimento do sujeito em relação com o outro.

O processo de desconstrução proposto por Jacques Derrida (2005) não é pensado a partir de agentes externos que modificarão as estruturas, mas de implosões a partir das contradições $e$ fissuras internas da própria estrutura, um processo de dentro para fora. Dessa forma, pensar sobre 
as discussões de gênero no cotidiano escolar gera descontinuidade da existência de normalidade exclusiva entre o "ser homem" e o "ser mulher", apresentando as diversidades que não correspondem ao dito "normal" e tampouco corroboram com a compreensão de anormalidade imposta (Foucault, 2015).

Considerando as impressões e compreensões dos(as) professores(as), como uma ação de organização de conhecimento prévio, apresentou-se as construções sobre a categoria gênero/sexualidade (Butler, 2015; Louro, 2002; 2007; Scott, 1995) de maneira que eles(as) pudessem estabelecer relações entre o que se falou e o que os estudos sobre a temática têm construído a partir do recorte de uma perspectiva pós-estruturalista.

Michel Foucault (2004) já chamava atenção para a situação do sujeito no discurso, evidenciando quem fala, o que se fala e para quem se fala no processo de elaboração de representações em espaços de disputas de poder em relação ao sujeito de autoridade. $\mathrm{O}$ recorte pós-estruturalista de que se lançou mão para a construção da formação pedagógica proporcionou um posicionamento favorável à proposta performativa de gênero expressa por Judith Butler (2015), a qual foi apresentada e discutida com os(as) professores(as) que participaram da capacitação.

O segundo dia de formação teve um caráter mais prático, pois tinha como objetivo a aplicabilidade das discussões do dia anterior em nossas ações pedagógicas. O intuito dessa divisão não era dissociar teoria e prática, mas propor que essas compreensões podem e devem estar inseridas nas práticas docentes nos espaços da escola.

Iniciou-se os debates com leituras de reportagens sobre as discussões da implementação da temática gênero/sexualidade nos currículos escolares por intermédio do Plano Nacional de Educação e de alguns relatos de alunos(as) da escola sobre acontecimentos na escola como violência e discriminação de gênero. As reportagens foram recortes da disputa política no período de 2014, quando tramitava a aprovação do PNE, e foram três no total: Comissão da Câmara aprova texto-base do PNE e retira questão de gênero publicada pela agência Brasil em 2014, Comissão aprova texto principal do Plano Nacional de Educação publicada no portal G1 em 2014 e Lobby conservador retira igualdade de gênero do Plano Nacional de Educação publicada na Rede Brasil Atual em 2014. Os dois relatos dos(as) alunos(as) lidos foram construídos durante uma atividade na disciplina de Educação Física sobre homofobia na escola.

A dinâmica de participação foi acordada na apresentação dos pontos de vista dos(as) professores(as) e de suas justificativas quanto ao que entenderam sobre as leituras. Na escolha das reportagens, foram destacadas informações que representavam os dois polos destacados no início do texto: aquele a favor do debate de gênero e sexualidade na escola, e aquele contra o debate. As justificativas mais utilizadas concordavam com o posicionamento religioso/cristão da criação divina de homens e mulheres; no entanto, houve falas que apontaram para a necessidade de compreensão acerca do que significa a inclusão do debate de gênero/sexualidade na escola, o que percebe-se a seguir:

"Eu acho que esse negócio tem que ficar mesmo é em casa, com a família, respeitar a moral" (Professor X, 10/04/2015, roda de conversa).

"A gente pensa que as violências acontecem longe da gente, mas eu nunca pensei que isso acontecia em nossa escola, precisamos falar sobre isso" (Professor T, 10/04/2015, roda de conversa).

"Eu não sei muito sobre isso, mas creio que tem muito equívoco nessas reportagens" (Professora L, 10/04/2015, roda de conversa).

A compreensão laica do ensino brasileiro, especialmente nas instituições públicas, está diluída na construção social de nosso país, que consolida as posições cristãs como hegemônicas e naturais. As falas dos(as) professores(as) confirmam esse posicionamento ao usarem suas crenças religiosas como instrumentos limitantes de discussões sobre a temática gênero/sexualidade.

À medida em que as discussões seguiam, percebeu-se que, embora os(as) professores(as) não concordassem inteiramente, certas posições argumentativas permitiram empatia Isso aconteceu, por exemplo, quando se iniciou a leitura dos relatos dos(as) alunos(as) sobre as "brincadeiras" que incomodavam, que eram, de certo modo, agressões e bullying (Abramovay, 2002). 
As tomadas de ação apresentadas pelos(as) professores(as) em acontecimentos desse tipo nos espaços escolares mais se aproximavam do silenciamento, com falas do tipo "prefiro fingir que não vi", do que a uma ação de intervenção e de interrupção na situação, com a justificativa de "não se saber lidar" em contextos que envolvem gênero e sexualidade.

A abstenção de ação já é uma tomada de posição: não há neutralidade nos espaços de disputa de poder. A construção do "não saber lidar" pode estar envolvida na ausência de conhecimento ou em uma tentativa de evitar a indisposição com o outro. A proposta da formação teve por base o fornecimento de instrumentos e conhecimentos sobre gênero/sexualidade como o primeiro passo de modificação de conceitos, valores e ações propagados no cotidiano escolar.

Em ambientes de disputas de saber e de poder, debater e pesquisar gênero e sexualidade nas áreas educacionais ou acadêmicas é percebido como "algo menor", o que nos leva a pensar sobre como a categoria gênero está sendo construída nos espaços educativos, de pesquisa e de ensino. No âmbito da produção de conhecimento e do fazer científico, vigora ainda uma noção do "eles" e do "nós", percepção essa descrita por Donna Haraway (1995) da seguinte forma:

O "eles" imaginado constitui uma espécie de conspiração invisível de cientistas e filósofos masculinistas, dotados de bolsa de pesquisas e de laboratórios; o "nós" imaginado são os outros corporificados, a quem não se permite não ter um corpo, um ponto de vista finito e, portanto, um viés desqualificador e poluidor em qualquer discussão relevante. [...] Nós, as feministas nos debates sobre ciência e tecnologia, somos os grupos de interesse especial da era Reagan no âmbito rarefeito da epistemologia, no qual o que tradicionalmente tem vigência como saber é policiado por filósofos que codificam as canônicas do conhecimento (Haraway, 1995:8).

O simples fato de se fechar os olhos para as discussões sobre gênero e sexualidade, seja no espaço acadêmico ou na escola, só comprova que avançamos muito pouco nos lugares destinados à educação, a produção de conhecimento e ao fazer científico. Falar sobre gênero é falar sobre o silenciamento de outros sujeitos no processo de formação da educação formal. Percebe-se que nem todas as pessoas estão preparadas para se envolver com os estudos de gênero ou trabalhar com a categoria gênero, pois, em se tratando destes, na escola ou na academia "há quem tente invisibilizar ou conceber ainda estes como 'estudos de mulher', 'estudos feministas', 'estudos feitos por mulheres' entre outras terminologias com teor quase sempre pejorativo" (Maia, 2020:43). Quem estuda e pesquisa gênero sempre está em um processo constante de negociação com o outro, pois "instituições 'fabricam' sujeitos. Busca-se compreender que a justiça, a igreja, as práticas educativas ou de governo, a política etc. são atravessadas pelo gênero (mas não apenas a partir dessas relações, e sim, também, das relações de classe, étnica etc.)" (Louro, 1997:25).

$\mathrm{Na}$ educação formal, campo heteronormativo, os docentes quase sempre se recusam a problematizar aquilo que é dado como natural e certo. As discussões realizadas na formação pedagógica destacaram o fato de que as questões de gênero e sexualidade estão presentes no cotidiano educacional. Portanto, os(as) professores(as) precisam desenvolver conhecimentos acerca da temática, pois a diversidade de sujeitos é inerente aos espaços escolares.

O encerramento da formação foi marcado pela apresentação das impressões que os(as) professores(as) tiveram sobre a estrutura, organização e as atividades realizadas, bem como eles(as) avaliavam a iniciativa. As contribuições foram positivas e a aproximação com o tema gerou outras sugestões de temáticas que apresentavam o recorte de gênero/sexualidade. No entanto, falar sobre essas temáticas ainda é um processo encarado com dificuldade, tendo em vista que, de acordo com alguns(mas) professores(as), "você precisa ser bem resolvido para isso". Esse posicionamento reforça a ideia de Jacques Derrida (2004) de problematização dessa organização estrutural de classificação entre opostos, que defende que não precisamos de um ponto fixo para a partida, mas compreender-nos em um processo constante de transformação, como é possível perceber nas falas abaixo:

"É muito importante momentos como esse, esse aprendizado, mas eu não me sinto segura e a vontade para trabalhar a temática, eu nem sei como fazer isso na minha disciplina, preciso estudar mais" (Professor F, 10/04/2015, roda de conversa). 
"Tu que és resolvida com isso fica muito mais fácil, é um momento de pensar na gente mesmo, porque levando em consideração o que vimos aqui, muitas coisas eu nem percebia" (Professor B, 10/04/2015, roda de conversa).

Durante os dias de realização da formação, as falas dos(as) professores(as) sobre os debates de gênero/sexualidade na escola tinham por princípio a criação de uma disciplina sobre o tema, mas, ao final dos nossos encontros, a compreensão de que as discussões de gênero/sexualidade são diárias e constantes e de que transitam nos diversos espaços reforçando, formulando e deslocando nossas representações sobre o corpo $e$ as ações do outro, em um estado móvel e instável de estar sendo e de não ser (Butler, 2015), já era partilhada pelos(as) professores(as). Assim, a necessidade de criação de uma disciplina exclusiva sobre gênero/sexualidade foi descartada.

\section{Algumas considerações}

A partir do entendimento de Derrida (2004; 2005), Foucault (2004; 2015) e Butler (2015), foi possível a construção dessa análise, permitindo observar que as imersões discursivas que envolvem gênero/sexualidade no cotidiano escolar são construídas por ações isoladas dos agentes sociais que articulam vivências e interesses sobre a temática. No entanto, eles não excluem as possibilidades de intervenção do Estado, fomentando o debate e garantindo os espaços para essas discussões

A compreensão de gênero como performativo, relacional e fluído, como propõe Butler, desloca a fixidez da heteronormatividade estruturalmente reforçada, reificada e produzida em nossas representações por meio das relações sociais cotidianas. Estabelecer as discussões sobre gênero/sexualidade por intermédio de como nossas representações são construídas e incorporadas no espaço escolar amplia as percepções das incongruências da natureza humana heterossexual.

As resistências às temáticas de gênero e sexualidade apresentadas pelos(as) professores(as) da escola envolvem vivências de socialização, isto é, as crenças e os valores aprendidos. A problematização de práticas docentes leva ao balançar das estruturas que antes eram inquestionáveis e imutáveis e ao desconforto de questionar a si mesmo. Isso é evidenciado na fala de um dos(as) professores(as): "você precisa ser bem resolvido para isso" - não fomos educados(as) ou ensinados(as) para nos questionar sobre o que e como somos em nossas vivências sociais em gênero/sexualidade.

A realização da formação pedagógica não possibilita afirmar categoricamente que serão implementadas novas visões sobre o outro $e$ os usos de seus corpos em relação a gênero $e$ sexualidade. Ao menos os(as) professores(as) tomaram conhecimento de que existem outras possibilidades de se compreender a diversidade de seres sociais, rechaçando o julgamento e a hierarquização dos sujeitos diferentes/divergentes.

\section{Referências bibliográficas}

ABRAMOVAY, Miriam. Violências nas escolas. Brasília, UNESCO Brasil, 2002.

ALTMANN, Helena. Orientação sexual nos parâmetros curriculares nacionais. Revista Estudos Feministas, v. 9, n. 2, 2001, p. 575-585 [http://www.scielo.br/pdf/ref/v9n2/8641.pdf - acesso em 20 ago 2015].

BUTLER, Judith P. Problemas de gênero: feminismo e subversão da identidade. Rio de Janeiro, Civilização Brasileira, 2015.

DERRIDA, Jacques. A Escritura e A Diferença. A Estrutura, o Signo e o Jogo no Discurso das Ciências Humanas. In: DERRIDA, Jacques. A Escritura e A Diferença. São Paulo, Perspectiva, 2005, pp.229-252. Coleção Debates: Filosofia.

; Roudinesco, Elizabeth. De que amanhã... Diálogo. Rio de Janeiro, Jorge Zahar, 2004, Tomos 1,2,3,8 e 9, pp. 9-62; 166-234.

FOUCAULT, Michel. História da sexualidade 1: a vontade de saber. 2 ed. São Paulo, paz e terra, 2015.

$A$ ordem do Discurso. Aula Inaugural no Collège de France, 2 de dezembro de 1970. 11ed. São Paulo, Ed. Loyola, 2004. Tradução: Laura Fraga de A. Sampaio.

Vigiar e Punir. nascimento da prisão. 42 ed. Petrópolis: Vozes, 2014. Tradução: Raquel Ramalhete. 
LAURETIS, Teresa de. A tecnologia do gênero. In: HOLLANDA, Heloísa Buarque de (org.). Tendências e impasses. o feminismo como crítica da cultura. Rio de Janeiro, Rocco, 1994, pp.206-242.

LAURETIS, Teresa. Technologies of gender. essays on theory, film and fiction. Bloomington, Indiana University Press, 1987.

LOURO, Guacira Lopes. Gênero, sexualidade e educação: uma perspectiva pós-estruturalista. 9ed. Petrópolis, RJ, Vozes, 2007.

Epistemologia feminista e teorização social: desafios, subversões e alianças. In: ADELMAN, Miriam; SILVESTRIN, Celsi Brönstrup (org.). Curitiba, UFPR, 2002, pp.11-22. Coletânea Gênero Plural.

MAIA, Marília Milhomem Moscoso. Vivências e lutas cotidianas de quem pesquisa e estuda gênero: apontamentos críticos e reflexivos no campo da pesquisa e das Ciências. Revista Humanidades $e$ Inovação, v. 7, n. 3, 2020 [https://revista.unitins.br/index.php/humanidadeseinovacao/article/view/1482 acesso em: 18 set 2020].

MAIORIA Oprimida. Direção de Eleonore Pourriat. Paris: Shandow Films, 2010. (10 min.), son., color. Legendado [https://www.youtube.com/watch?time_continue $=2 \& \mathrm{v}=\mathrm{bHJqNpJ8xAQ}$ - acesso em: $10 \mathrm{fev}$. 2015].

SCOTT, Joan. Gênero: uma categoria útil de análise histórica. Revista Educação e Realidade, v. 20, n. 2, Porto Alegre, 1995, pp.71-99.

SPIVAK, Gayatri Chakravorty. Pode o subalterno falar? Belo Horizonte, editora UFMG, 2010. Tradução Sandra Regina Goulart, Marcos Pereira Feitosa e André Pereira Feitosa. 